\title{
Food insecurity in a pre-bariatric surgery sample: prevalence, demographics and food shopping behaviour
}

\author{
Julia A Price ${ }^{1, *}$, Hana F Zickgraf ${ }^{1,2}$ and Andrea Rigby ${ }^{1}$ \\ 'Department of Surgery, Penn State College of Medicine, 500 University Drive, Hershey, PA 17033, USA: \\ 2Department of Psychiatry and Behavioral Neuroscience, University of Chicago, Chicago, IL, USA
}

Submitted 12 September 2018: Final revision received 20 February 2019: Accepted 19 March 2019: First published online 19 June 2019

\begin{abstract}
Objective: To identify the prevalence and demographic characteristics of food insecurity in a presurgical bariatric population. To date there has been no research on food insecurity in a presurgical bariatric population.

Design: Participants completed the ten-item adult food security survey module created by the US Department of Agriculture (USDA), with additional questions related to food shopping behaviours and perceived affordability of post-bariatric supplements. USDA scoring guidelines were used to classify participants as food secure, marginally food secure and food insecure.

Setting: Academic medical centre bariatric surgery clinic in Central Pennsylvania, USA.

Participants: Adult bariatric surgery candidates ( $n$ 174).

Results: There was a prevalence of $17.8 \%$ for food insecurity and $27.6 \%$ for marginal food security. Food insecurity was associated with younger age, higher BMI, non-White race/ethnicity, having less than a college education, living in an urban area, receiving Medicaid/Medicare and participating in nutrition assistance programmes. Food-insecure participants endorsed food shopping behaviours that could interfere with postsurgical dietary adherence and perceived post-bariatric supplies as unaffordable or inaccessible.

Conclusions: These results highlight the importance of screening bariatric surgical patients for food insecurity. Further study of this important problem within the bariatric population should address effects of food insecurity and related shopping behaviours on postsurgical outcomes and inform the development of programmes to better assist these high-risk patients.
\end{abstract}

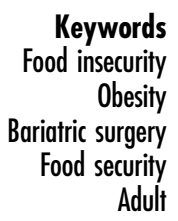

The US Department of Agriculture (USDA) defines food security as having reliable access to adequate food for a healthy lifestyle ${ }^{(1)}$. Food insecurity is a worldwide public health concern linked to detrimental health, psychological and social outcomes ${ }^{(2-4)}$. In the most recent federal survey of food insecurity conducted in 2017, the national prevalence of food insecurity was estimated as $11.8 \%$ (15 million households), with $7.3 \%$ reporting low food security (e.g. reduced quality, variety or desirability of diet, with little to no indication of reduced food intake) and $4.5 \%$ reporting very low food security (e.g. disrupted eating patterns and reduced food intake due to reduced availability of food $)^{(1)}$. An additional $10.6 \%$ of households with children, and $6.6 \%$ of those without children, reported marginal food security, defined as anxiety over the availability of food or shortage of food with little evidence of changes in diet or food intake ${ }^{(5)}$.

Food insecurity status is associated with obesity and obesity-related co-morbidities and has been extensively researched in diverse populations ${ }^{(1,6-8)}$. In a 2012 survey of 66500 adults in twelve US states, food insecurity was associated with a $32 \%$ increase in the odds of obesity, reflecting a prevalence of $35 \cdot 1 \%$ among those with food insecurity compared with $25 \cdot 2 \%$ in food-secure adults ${ }^{(9)}$. Adult food insecurity is a risk factor for diabetes and CVD, conditions especially impacted by poor diet quality ${ }^{(2,4,10)}$, and is also associated with poorer management of chronic health conditions, leading to adverse health outcomes $^{(4,11-13)}$. The literature on the relationship between food insecurity and body weight is somewhat inconsistent 
and appears to be moderated by gender, with a linear relationship between degree of food insecurity and body weight consistently observed for women, compared with mixed findings among men ${ }^{(14)}$. There is also some evidence that the relationship between food insecurity and weight might be curvilinear, with lower BMI at both very high and very low levels of food insecurity ${ }^{(14)}$.

One explanation for the relationship between obesity and food insecurity is that persons who experience food insecurity rely on energy-dense processed foods as these foods are typically cheaper, more readily accessible and less perishable than nutrient-dense foods such as fruits, vegetables and dairy products ${ }^{(3,12,13,15)}$. In a nationally representative sample of US adults aged 18-64 years, adult food insecurity status predicted both obesity risk and poorer overall dietary quality when other demographic factors, including household poverty, were controlled ${ }^{(16)}$. Adults who experience food insecurity report unhealthy food choices relative to food-secure peers, including higher fat and fruit juice intakes, and lower fruit, vegetable and dairy consumption ${ }^{(13,17,18)}$. Another potential explanation involves the cyclical nature of food insecurity, which can be characterized by periods of relative availability of food, or even of overeating, followed by periods of scarcity ${ }^{(10,15)}$. Food insecurity has also been linked to disordered eating behaviours, including binge eating and dietary restraint, both of which involve irregular eating patterns and are risk factors for excessive energy intake and weight gain ${ }^{(19)}$. Irregular eating habits can contribute to obesity and impede weight-loss efforts ${ }^{(10,15)}$, and are particularly dangerous and detrimental to weight loss following bariatric surgery, when diverging from a regular eating schedule can lead to dehydration and malnutrition.

The prevalence of adult obesity has continued to increase in recent years and with it the prevalence of comorbidities including type 2 diabetes, heart disease and hypertension $^{(20,21)}$. Bariatric surgery is currently the most effective treatment for achieving significant, long-term weight loss and improvement in obesity-related metabolic and cardiovascular co-morbidities (e.g. type 2 diabetes, hypertension, obstructive sleep apnoea $)^{(22-25)}$. However, as many as $30 \%$ of patients do not achieve or maintain their predicted weight loss and behavioural adherence to postoperative dietary recommendations is a major predictor of postsurgical success ${ }^{(26)}$. Current postoperative bariatric guidelines emphasize the importance of eating a diet high in fresh fruits and vegetables and particularly high in protein; an average protein intake of $60-120 \mathrm{~g} / \mathrm{d}$ is recommended both for weight loss and long-term weight maintenance ${ }^{(27-29)}$. In addition, bariatric surgery patients require lifelong oral vitamin and mineral supplementation, with poor adherence increasing the risk for malnutrition and other complications ${ }^{(30,31)}$. Use of protein supplements is also recommended: restricted stomach volume, malabsorption (in the case of gastric bypass) and the relatively high rate of postoperative intolerance for animal protein make it difficult for many patients to meet the recommended high protein intake with food alone ${ }^{(27)}$. Use of protein supplements after surgery may be associated with improved weight-loss outcomes ${ }^{(32)}$. It seems very likely that food insecurity would negatively affect bariatric patients' ability to maintain these dietary changes over the long term; by definition, individuals with low and very low food security lack reliable access to the amount and types of foods they need to maintain a healthy lifestyle. Despite the universally acknowledged importance of dietary adherence for post-bariatric weight-loss maintenance, the prevalence and features of food insecurity have not been studied in this population.

The purpose of the present study was to assess the prevalence of self-reported food insecurity in a prebariatric surgery sample and to explore demographic, clinical and behavioural correlates of food insecurity in this population. Three groups of exploratory hypothesis tests were conducted. The first series of tests involved demographic correlates: participant gender, age, ethnicity, education attainment, adjusted gross income and population density of participants' zip codes of residence, and participation in food assistance programmes and Medicare/ Medicaid. The second series of tests involved clinical correlates: BMI at programme entry and obesity-related co-morbidities (type 2 diabetes, heart disease/hypertension and obstructive sleep apnoea). The third series of tests involved participant-reported perceptions and behaviours related to food and nutritional supplement purchases.

The USDA report on household food insecurity in the USA in 2016 by Coleman-Jensen et al. identifies a higher prevalence of food insecurity in households that are lowincome, headed by a single parent, or reporting a Black non-Hispanic or Hispanic ethnicity ${ }^{(1)}$. This is consistent with literature reviews that also reported similar demographic correlates of food insecurity along with a strong relationship with being female and having less than a college education level ${ }^{(4,14)}$. We expected to replicate these demographic correlates of food insecurity in the study population. We predicted that living in a city centre would be associated with food insecurity, as the cities represented in our sample are predominantly low-income. Analyses comparing rural $v$. urban/suburban zip codes were exploratory. Because the relationship between food insecurity and body weight might differ between men and women, we explored this relationship separately for women, hypothesizing that a positive relationship between food insecurity and BMI would be identified in the female sub-sample. Analyses regarding co-morbid diagnoses were exploratory; although type 2 diabetes and hypertension are more common in adults with food insecurity ${ }^{(2,4,10)}$, obesity-related co-morbidities are very common in pre-bariatric populations and so we did not have specific hypotheses regarding their association with food insecurity in this sample. Finally, we developed five questions related to food shopping behaviours; because they were derived from the literature on shopping and eating 
behaviours associated with food insecurity in general samples, we expected to find that endorsement of all five questions was higher in food-insecure participants.

Our sample was broken down into food-secure, marginally food-secure and food-insecure groups. The USDA Statistical Supplement and other literature have identified marginally food-secure people as having characteristics more similar to food-insecure groups than food-secure groups $^{(4,5,14)}$. We expected to broadly replicate this finding, hypothesizing that marginally food-insecure participants would show demographic, clinical and behavioural features that were either more similar to food-insecure participants or that fell between food-secure and food-insecure participants.

The present study is the first exploration of the demographic, clinical and behavioural correlates of food insecurity in a bariatric sample. A better understanding of the demographic correlates of food insecurity specific to presurgical bariatric populations might help to guide programming and clinical decision making aimed at identifying and assisting patients who might be at risk for food insecurity. Exploring the relationship of food insecurity category with continuous BMI and common obesity-related comorbidities is a first step in beginning to quantify the potential impact of food insecurity on health status in this population. The five behavioural questions were included to better understand food shopping behaviours and beliefs about the accessibility of post-bariatric vitamins and supplements through which food insecurity might affect bariatric dietary adherence and outcomes, with the goal of developing causal hypotheses for future studies with prospective or experimental (e.g. intervention) designs.

\section{Methods}

\section{Measures}

\section{Food insecurity screening}

Participants responded to the ten-item USDA adult food security survey module ${ }^{(1,33)}$. The measure includes three screening items and seven items designed to assess household food insecurity for adult respondents. Although this measure is usually administered by an interviewer, we modified the items for self-report. Standard administration involves reading the questions and response options aloud to the participant, often over the telephone; the text of the items and response options was given to participants with no changes to the wording and no additions to or deletions from any item ${ }^{(33)}$. A bariatric psychologist was available during administration to answer participants' questions about the items and survey as needed. An affirmative answer (e.g. 'often true' or 'sometimes true') to each item is scored as 1 (for two items assessing the frequency of behaviours associated with food insecurity, responses of 'never' or 'only one or two months' are scored as negative and responses of 'some months but not every month' and 'almost every month' are scored as affirmative). The adult food security survey module yields a score ranging from 0 to 10 . The continuous score is used to create four food security categories. A score of 0 is scored as food secure, $1-2$ as marginally food secure, 3-6 as low food security and 7-10 as very low food security ${ }^{(33)}$. Given the relatively low base rate of very low food security in our sample, we grouped participants with low and very low food security into a single category, as recommended in the USDA guide ${ }^{(1,5)}$. The ten-item continuous score (used in correlational analyses with BMI) demonstrated good internal consistency: $\alpha=0 \cdot 84$.

\section{Demographics}

Participants self-reported their age, gender, race/ethnicity and years of education on the Weight and Lifestyle Inventory (WALI) ${ }^{(34)}$, a commonly used instrument in prebariatric psychological assessment. Participants' electronic medical records were accessed to obtain their insurance information and the zip code of their current address. Zip codes were used to identify whether participants lived in an urban or rural municipality, whether they lived in a city centre and whether their municipality's median income was greater or less than $\$$ US 50000 . Urban $v$. rural areas were defined using the US Census Bureau definition of rural municipalities as having fewer than 2500 people per square mile, with any municipality with a population density greater than 2500 per square mile defined as urban ${ }^{(35)}$ $\left(1\right.$ mile $\left.^{2}=2.59 \mathrm{~km}^{2}\right)$. Participants with zip codes within the boundaries of larger urban centres (defined as cities with population greater than 25000) were coded as being city residents ${ }^{(36)}$. The seven cities represented in this sample, i.e. Harrisburg, Lancaster, Lebanon, York, Bethlehem, State College and Reading, PA, are majority low-income with low access to food according to US Census Bureau 2010 statistics $^{(37)}$. Median zip code income was assessed using 2015 adjusted gross income data from tax returns; all municipalities in this data set had median income of either \$US 25 000-49999 or \$US 50 000-74999(38). Participants were also asked to report whether they used food assistance programmes (e.g. Supplemental Nutrition Assistance Program). Sample descriptives are presented in Table 1, and group comparisons for binary demographic variables are presented in Table 2 . See Table 3 for group comparisons on age and BMI.

\section{Additional food security items}

Based on a literature review of food buying behaviours associated with food insecurity ${ }^{(8,15,39)}$, we developed five questions that were included in the same survey as the ten US adult food security survey module items. For the full text of all added questions, see Table 4. These items shared the response format of the USDA items (e.g. 'never', 'sometimes', 'often' true) and assessed the following behaviours: eating fast food to save money, buying unhealthy food rather than healthy food because of the expense, 
Table 1 Demographics of the current sample of adult bariatric surgery candidates, Central Pennsylvania, USA, December 2017August 2018, and comparison with nationally representative bariatric surgery demographics

\begin{tabular}{lcc}
\hline & $\begin{array}{c}\text { Current sample } \\
(n \text { 174) }\end{array}$ & $\begin{array}{c}\text { National cohort } \\
(n \text { 94 613) }\end{array}$ \\
\hline Age (years) & & \\
Mean & 41.5 & 44.6 \\
SD & 12.5 & 12.0 \\
Gender, female (\%) & 73.0 & 79.20 \\
Race/ethnicity (\%) & & \\
African-American & 11.5 & 14.80 \\
Other non-White & 18.4 & 17.86 \\
White & 67.2 & - \\
Insurance (\%) & & \\
Managed care/commercial & 63.2 & 64.44 \\
Medicare & 8.0 & 16.86 \\
$\quad$ Medicaid & 27.6 & 11.76 \\
Education attainment (\%) & & - \\
$\quad$ Less than high school & 10.3 & - \\
High-school graduate & 40.2 & - \\
Some college & 25.3 & - \\
College or postgraduate & 23.6 & \\
\hline
\end{tabular}

lacking the time or transportation to buy groceries, and buying large amounts of food early in the month and running out. We also asked participants whether they felt that it would be a hardship to afford postsurgical vitamins and supplements.

\section{$B M I$}

BMI was calculated by dividing weight in kilograms by the square of height in metres $\left(\mathrm{kg} / \mathrm{m}^{2}\right)$. Weight and height were taken by programme staff (registered nurses, registered nutritionists or licensed practical nurses) with participants wearing light clothing and no shoes.

\section{Medical co-morbidities}

Research staff reviewed participants' electronic medical charts for three medical co-morbidities commonly associated with obesity: type 2 diabetes, hypertension/heart disease and sleep apnoea. See Table 2 for the prevalence of each co-morbid diagnosis in our sample.

Table 2 Demographic correlates of food security status in the sample of adult bariatric surgery candidates, Central Pennsylvania, USA, December 2017-August 2018

\begin{tabular}{|c|c|c|c|c|c|c|c|c|c|c|}
\hline & \multicolumn{2}{|c|}{ Total sample } & \multicolumn{2}{|c|}{$\begin{array}{l}\text { High food } \\
\text { security } \\
(n 94)\end{array}$} & \multicolumn{2}{|c|}{$\begin{array}{l}\text { Marginal } \\
\text { food } \\
\text { security } \\
(n 41)\end{array}$} & \multicolumn{2}{|c|}{$\begin{array}{l}\text { Food } \\
\text { insecure } \\
(n 31)\end{array}$} & \multirow[b]{2}{*}{$\chi_{(2)}^{2}, \varphi$} & \multirow[b]{2}{*}{$P$} \\
\hline & $n$ & $\%$ & $n$ & $\%$ & $n$ & $\%$ & $n$ & $\%$ & & \\
\hline Gender, female & 127 & $73 \cdot 0$ & 69 & $72 \cdot 6$ & 34 & $70 \cdot 8$ & 24 & 77.4 & $0.43,0.05$ & 0.81 \\
\hline Single parent & 24 & $13 \cdot 8$ & 13 & $14 \cdot 0$ & 8 & $17 \cdot 4$ & 3 & $12 \cdot 0$ & $0.41,0.05$ & 0.80 \\
\hline College graduate & 41 & $23 \cdot 6$ & 31 & 33.0 & 7 & $14 \cdot 6$ & 3 & $9 \cdot 7$ & $10 \cdot 05,0.24^{\star}$ & 0.007 \\
\hline Minority racial/ethnic group & 52 & 29.9 & 15 & $16 \cdot 3$ & 22 & $46 \cdot 8$ & 15 & $50 \cdot 0$ & $19 \cdot 92,0.34^{\star \star}$ & $<0.001$ \\
\hline Urban centre $(>25000)$ & 61 & $35 \cdot 1$ & 27 & 28.7 & 16 & $34 \cdot 8$ & 18 & $58 \cdot 1$ & $8.77,0.23^{\star}$ & 0.01 \\
\hline Rural $(<2500)$ & 24 & $13 \cdot 8$ & 16 & $17 \cdot 0$ & 4 & 8.7 & 4 & $12 \cdot 9$ & $1 \cdot 82,0 \cdot 10$ & 0.40 \\
\hline Median income < \$US 50000 & 87 & $50 \cdot 0$ & 41 & $44 \cdot 1$ & 28 & $60 \cdot 9$ & 18 & $58 \cdot 1$ & $4.90,0.16$ & 0.12 \\
\hline Food assistance recipient & 51 & $29 \cdot 3$ & 17 & $18 \cdot 1$ & 16 & 33.3 & 18 & $58 \cdot 1$ & $18 \cdot 40,0.33^{* *}$ & $<0.001$ \\
\hline Medicare/Medicaid beneficiary & 62 & $35 \cdot 6$ & 28 & $29 \cdot 8$ & 16 & 33.3 & 18 & $60 \cdot 0$ & $9 \cdot 22,0.23^{*}$ & 0.01 \\
\hline Any co-morbidity & 138 & $79 \cdot 3$ & 75 & $78 \cdot 9$ & 39 & $81 \cdot 3$ & 24 & $77 \cdot 4$ & $0.19,0.03$ & 0.91 \\
\hline Type 2 diabetes & 60 & 34.5 & 28 & 29.5 & 20 & $41 \cdot 7$ & 12 & 38.7 & $2 \cdot 40,0.12$ & 0.30 \\
\hline Heart disease & 113 & 64.9 & 65 & 68.4 & 32 & $66 \cdot 7$ & 16 & 51.6 & $2.99,0.13$ & 0.23 \\
\hline Sleep apnoea & 74 & 42.5 & 41 & 43.6 & 20 & $41 \cdot 7$ & 13 & 41.9 & $0.06,0.02$ & 0.97 \\
\hline
\end{tabular}

${ }^{*} P<0.05,{ }^{* *} P<0.001$

Table 3 One-way ANOVA and post hoc least significant difference test group comparisons: age and BMI by food security status in the sample of adult bariatric surgery candidates, Central Pennsylvania, USA, December 2017-August 2018

\begin{tabular}{|c|c|c|c|c|c|c|c|c|c|c|}
\hline & \multicolumn{2}{|c|}{ Total sample } & \multicolumn{2}{|c|}{$\begin{array}{l}\text { High food } \\
\text { security }\end{array}$} & \multicolumn{2}{|c|}{$\begin{array}{l}\text { Marginal food } \\
\text { security }\end{array}$} & \multicolumn{2}{|c|}{ Food insecure } & \multirow[b]{2}{*}{$F_{(2,120)}, \eta^{2}$} & \multirow[b]{2}{*}{$P$} \\
\hline & Mean & SD & Mean & SD & Mean & SD & Mean & SD & & \\
\hline & & & \multicolumn{2}{|c|}{$n 94$} & \multicolumn{2}{|c|}{$n 47$} & \multicolumn{2}{|c|}{$n 31$} & & \\
\hline Age (years) & 41.49 & $12 \cdot 23$ & $n 84$ & $11 \cdot 75$ & $\begin{array}{r}39.91^{a, b} \\
n\end{array}$ & 11.47 & \multicolumn{2}{|c|}{$n 27$} & $3.99,0.05^{*}$ & 0.02 \\
\hline BMI $\left(\mathrm{kg} / \mathrm{m}^{2}\right)(n$ 152) & 48.00 & $7 \cdot 33$ & \multicolumn{2}{|c|}{$n 59$} & ${ }^{49.60}$ & $7 \cdot 75$ & $\begin{array}{r}48.89 \\
n\end{array}$ & $n 21$ & $2.08,0.03$ & 0.13 \\
\hline BMI $\left(\mathrm{kg} / \mathrm{m}^{2}\right)$, women $(n$ 109) & 47.62 & $7 \cdot 11$ & \multicolumn{2}{|c|}{$n 25$} & $\begin{array}{r}48 \cdot 75^{\mathrm{a}, \mathrm{b}} \\
n\end{array}$ & 7.91 & $50 \cdot 31^{\mathrm{b}}$ & $7 \cdot 47$ & $3.33,0.06^{*}$ & 0.04 \\
\hline BMI $\left(\mathrm{kg} / \mathrm{m}^{2}\right)$, men $(n$ 43) & 48.94 & $7 \cdot 88$ & $48 \cdot 87$ & $6 \cdot 26$ & 51.63 & $7 \cdot 25$ & 43.88 & $5 \cdot 17$ & $2.03,0.09$ & - \\
\hline
\end{tabular}

a,b Mean values in a row with unlike subscript letters were significantly different $(P=0.02)$.

${ }^{\star} P<0.05,{ }^{\star \star} P<0.001$. 
Table 4 Shopping habits and bariatric-specific items by food security status in the sample of adult bariatric surgery candidates, Central Pennsylvania, USA, December 2017-August 2018

\begin{tabular}{|c|c|c|c|c|c|c|c|c|c|c|}
\hline & \multicolumn{2}{|c|}{$\begin{array}{l}\text { Total } \\
\text { sample }\end{array}$} & \multicolumn{2}{|c|}{$\begin{array}{l}\text { High food } \\
\text { security } \\
\text { (n 94) }\end{array}$} & \multicolumn{2}{|c|}{$\begin{array}{l}\text { Marginal } \\
\text { food } \\
\text { security } \\
\text { (n 47) }\end{array}$} & \multicolumn{2}{|c|}{$\begin{array}{l}\text { Food } \\
\text { insecure } \\
(n 31)\end{array}$} & \multirow[b]{2}{*}{$\chi_{(2)}^{2}, V$} & \multirow[b]{2}{*}{$P$} \\
\hline & $n$ & $\%$ & $n$ & $\%$ & $n$ & $\%$ & $n$ & $\%$ & & \\
\hline $\begin{array}{l}\text { 'When our money runs low, we shop at fast-food } \\
\text { restaurants to save money' }\end{array}$ & 34 & $19 \cdot 5$ & 5 & $5 \cdot 3$ & 13 & $27 \cdot 1$ & 16 & $51 \cdot 6$ & $34 \cdot 34,0.44^{\star *}$ & $<0.001$ \\
\hline $\begin{array}{l}\text { 'I worry about having the time and transportation } \\
\text { to buy my groceries' }\end{array}$ & 18 & $10 \cdot 5$ & 3 & $3 \cdot 2$ & 2 & $4 \cdot 3$ & 13 & 41.9 & $34 \cdot 63,0.50^{\star \star}$ & $<0.001$ \\
\hline $\begin{array}{l}\text { 'I try to only buy healthy foods, but I end up buying } \\
\text { unhealthy foods that are cheaper' }\end{array}$ & 124 & $71 \cdot 3$ & 58 & $60 \cdot 0$ & 42 & 87.5 & 25 & $80 \cdot 6$ & $13 \cdot 40,0 \cdot 28^{*}$ & 0.001 \\
\hline $\begin{array}{l}\text { 'In the past } 12 \text { months, I found myself purchasing } \\
\text { a lot of food at the beginning of the month then } \\
\text { running out of food later in the month' }\end{array}$ & 25 & 14.4 & 5 & $5 \cdot 3$ & 5 & $10 \cdot 4$ & 15 & $48 \cdot 4$ & $36 \cdot 17,0.46^{\star *}$ & $<0.001$ \\
\hline $\begin{array}{l}\text { 'I feel that it could be a hardship to purchase needed } \\
\text { vitamins, protein shakes or food items recommended } \\
\text { by the bariatric surgery programme' }\end{array}$ & 34 & $19 \cdot 7$ & 7 & 7.4 & 13 & $27 \cdot 7$ & 14 & $45 \cdot 2$ & $23 \cdot 76,0.37^{\star *}$ & $<0.001$ \\
\hline
\end{tabular}

${ }^{\star} P<0.05,{ }^{* \star} P<0.001$.

Participants were 174 bariatric surgery candidates at an academic medical centre and bariatric surgery centre of excellence in Central Pennsylvania who provided complete responses to the full ten-item USDA adult food security survey module. All patients participating in the preoperative programme were eligible for the study, and all were approached during their initial programme visit, when they completed self-report measures, for informed consent for their data to be used for research purposes. To date, $100 \%$ of patients in the programme have consented to the present study. A total of 200 participants were administered the measure; twenty-six (13\%) either did not fill out the measure at all or provided incomplete data to calculate the food security risk score. When data were analysed, only six participants (3.4\%) had completed the presurgical programme and been approved for surgery, and five $(2.9 \%)$ had left the programme without being approved. The remaining participants (93.7\%) were still active in the presurgical programme.

\section{Procedures}

The USDA adult food security survey module questions, a question about food assistance utilization and five additional items about shopping behaviours/perceptions were embedded in a packet of self-report measures that included the WALI $^{(34)}$. Data were collected at the outset of the presurgical programme; all patients who apply to enter the presurgical programme complete the packet of self-report measures in which the USDA adult food security survey module items were included, and all patients are approached to obtain their consent for questionnaire and medical chart data to be used in research. The institutional review board of Penn State College of Medicine provided approval for the measures and procedures employed in the present study.

Demographic information including age, gender, educational attainment, race/ethnicity and single parent status were obtained from responses to the demographics and household composition sections of the WALI. Participants' zip codes and insurance coverage were obtained from electronic medical records. Zip codes were used to search a database maintained by the Center for Rural Pennsylvania, which lists urban and rural municipalities, and the Internal Revenue Service's Individual Income Tax Statistics database of 2015 income tax return data, by zip code ${ }^{(36,38)}$. BMI was calculated from weight and height obtained at the first programme nutritionist visit. For most patients, this visit took place after the initial programme visit where they responded to the self-report survey measures.

\section{Data analysis}

Data were analysed using the statistical software package IBM SPSS Statistics version 25.0. To explore the demographic correlates of food insecurity in a bariatric population, we performed $\chi^{2}$ analyses for eight discrete binary variables: (i) White $v$. person of colour/non-White; (ii) college graduate $v$. non-graduate; (iii) single parent $v$. non-parent or co-parent; (iv) male- $v$. female-identified; (v) urban $v$. rural zip code; (vi) city centre $v$. suburban or rural zip code; (vii) median zip code income greater $v$. less than $\$ \mathrm{US} 50000$; and (viii) public $v$. commercial/employer insurance (commercial/employerprovided insurance $v$. Medicare, Medicaid). Cramer's $V$ effect sizes were produced for these analyses. We used one-way ANOVA to compare the food security groups on age and BMI. Because the relationship between food insecurity and obesity appears to differ for men and women, the analyses with BMI were conducted separately for men and women. Continuous relationships between food insecurity score (range 0-10) and age and BMI were computed using nonparametric Spearman's $\rho$. To explore food shopping behaviours and perceptions about the affordability of 'healthy' food and bariatric supplies, we used $\chi^{2}$ and Cramer's $V$. 
We used the R package 'pwr' to estimate power to detect small and moderate effect sizes with $P=0.05^{(40)}$. For $\chi^{2}$ with $2 \mathrm{df}$, there was adequate ( $85 \%$ ) power for medium effects $(V=0.30)$, but our sample was underpowered $(65 \%)$ for small effects $(V=0 \cdot 20)$. For one-way ANOVA with 2 numerator $\mathrm{df}$ and $171 \mathrm{denominator} \mathrm{df}$, there was adequate power (95\%) for moderate effect sizes $(\eta=0.09)$ and small-tomoderate effects ( $70 \%$ for $\eta=0 \cdot 045$ ), but not small effects (36\% for $\eta=0 \cdot 01$ ). For correlational analyses there was power for moderate $(r=0.30,98 \%)$ and small-tomoderate $(r=0 \cdot 20,76 \%)$, but not small $(r=0 \cdot 10,26 \%)$ effects. Although these analyses were exploratory, we computed Bonferroni-corrected critical $P$ values for each of the three groups of hypothesis tests (e.g. demographic correlates, $P=0.006$; clinical correlates, $P=0.01$; behavioural correlates, $P=0 \cdot 01$ ), and $P$ values for all analyses are presented in Tables $2-4$. We chose to focus our interpretations on findings that were significant at a more liberal $P$ value of 0.05 and associated with moderate effect sizes.

\section{Results}

\section{Sample characteristics}

See Table 1 for a summary of participant-reported demographics. Our sample is comparable to a nationally representative sample of bariatric surgery candidates ( $n$ 94 613) identified in a data set of a representative $20 \%$ of hospital discharges in the USA between 2012 and 2015 on race/ethnicity, age, gender and insurance status ${ }^{(41)}$. Nationally, $89.97 \%$ of bariatric surgeries were performed in urban hospitals, $47.03 \%$ were performed in teaching hospitals and $32.21 \%$ were performed in hospitals with more than 500 beds. Our facility is a large ( $\geq 500$ beds) academic medical centre located in an urban area but serving nearby rural communities. The demographics of our programme were broadly similar to national statistics; patients were majority White and female, with a mean age of 41.5 years in our sample compared with a national average age of 44.6 years. The proportion of patients with managed care/commercial insurance at our centre was similar to that of the national statistics. However, the proportion using Medicaid was higher, likely because the programme's designation as a bariatric surgery centre of excellence makes procedures eligible for reimbursement by Medicaid. A smaller proportion of our sample used Medicare, despite centre of excellence designations also being required for Medicare reimbursement. Although the average age of our sample was consistent with the national average, very few patients were older than 65 years ( $4.0 \%$ ), which could account for the low rates of Medicare utilization in our sample.

\section{Food insecurity screening}

Based on their responses to the three USDA screening items, $41.4 \%$ of the current sample was at risk for food insecurity. When full ten-item USDA scores were examined, all but seven participants who screened negative for food insecurity risk received a ten-item score of 0 , classifying them as highly food secure (93.1\%); the seven participants who screened negative all fell into the marginal food security category, endorsing no more than two of the remaining seven USDA adult food security survey module items.

Based on the full ten-item score, ninety-five participants ( $54.6 \%$ of the sample) were food secure, forty-eight (27.6\%) were marginally food secure and thirty-one (17.8\%) were food insecure. Of the participants who were classified as food insecure based on self-report, twenty-one (12.1\% of the full sample) scored in the 'low food security' range and ten (5.7\%) scored in the 'very low food security' range.

\section{Demographic correlates of food insecurity}

Participants who identified as belonging to a racial/ethnic minority, who did not have a college education, who lived in a city centre (e.g. population $>25000$ ) and who reported using food assistance programmes or being Medicare/ Medicaid beneficiaries were more likely to report marginal food security or food insecurity. Gender and being a single parent were not associated with food security in this sample (Table 2). There was also no association between food security and living in a rural area (population $<2500$ ) or in a zip code with median income of $<\$$ US 50000 . See Table 2 for group proportions.

Explored continuously, age was related to food security score. Higher scores, suggesting greater food insecurity, were associated with younger age $(\rho=-0.24, P=0.002)$. Food-secure participants were an average of 3.9 (SE 2.1) years older than those with marginal food security and 6.4 (SE 2.5) years older than those with food insecurity. Post hoc least significant difference testing suggested that the latter difference was significant, with no significant difference between participants with marginal food security and those with either food security or food insecurity.

\section{Clinical correlates of food insecurity}

Overall, almost $80 \%$ of patients had at least one obesityrelated co-morbidity. There was no bivariate association between food insecurity status and having any obesityrelated co-morbidity, or having type 2 diabetes, heart disease/hypertension or obstructive sleep apnoea.

In the full sample, there was a small, but significant positive correlation between continuous food insecurity score and BMI $(\rho=0.17, \quad P=0.04)$. Although food-insecure participants had higher mean BMI than either marginally food-secure (mean difference $=2.66($ SE 1.39$) \mathrm{kg} / \mathrm{m}^{2}$ ) or food-secure participants (mean difference $=1.95$ (SE $1 \cdot 61) \mathrm{kg} / \mathrm{m}^{2}$ ), these group differences were not statistically significant. See Table 3 for group means and ANOVA results. As we predicted, however, when the relationship between food insecurity and BMI was explored among 
female participants ( $n$ 127), there was a small-to-moderate positive correlation between continuous food security score and BMI $(\rho=0.27, P=0.01)$ and there was a significant overall effect of food security category on BMI, with foodinsecure women reporting a higher mean BMI than those with marginal food security (mean difference $=1.56$ (SE 2.0) $\mathrm{kg} / \mathrm{m}^{2}$ ) and food-secure women (mean difference $=3 \cdot 20$ ( $\mathrm{sE}$ $1.77) \mathrm{kg} / \mathrm{m}^{2}$ ); the latter difference was significant, whereas the difference between women with marginal food security and women with food insecurity was not significant (Table 3). Results for the male sample are not reported; although all BMI/food insecurity relationships were small and non-significant among men, the sample size was very small ( $n$ 47, with only six participants in the food-insecure category) and these estimates are not reliable.

\section{Behavioural correlates of food insecurity}

Participants with food insecurity and marginal food security were more likely to report eating fast food to save money, running out of food by the end of the month, difficulties with grocery shopping due to time and transportation, and concerns about being able to afford bariatric-specific foods and dietary supplements. More than half of all patients reported sometimes or often buying unhealthy foods because of the price, although participants with food insecurity and marginal food security were more likely do so (Table 4).

\section{Discussion}

Only half of the patients in our sample reported high food security, with $27.6 \%$ reporting marginal food security and $17.8 \%$ reporting food insecurity. This is higher than the national adult average of $12.3 \%$ for food insecurity, and notably higher than the national average of $6.6 \%$ for marginal food security ${ }^{(1,5)}$. The initial three USDA screening items accurately identified $93.1 \%$ of patients, with only seven patients who screened negative meeting criteria for marginal food security on the full ten-item scale. These findings support the use of the screening items to minimize burden for food-secure respondents in future bariatric studies.

Our findings regarding demographic correlates of food security risk were broadly consistent with the existing literature in non-bariatric samples: younger patients, patients who reported a non-White race or ethnicity, lived in predominantly low-income urban centres or had less than a college education were more likely to be marginally food secure or food insecure ${ }^{(4,14,15,42,43)}$. Food insecurity status was not associated with increased risk of having an obesity-related co-morbidity in this sample. There was a small correlation between food insecurity risk score and BMI at the beginning of the presurgical programme, although the mean differences between food security levels were not significant when explored across the full sample. However, for female participants, there was a stronger continuous relationship, with a significant difference in mean BMI between food-secure and food-insecure women of almost $5 \mathrm{~kg} / \mathrm{m}^{2}$ and a difference between an average $\mathrm{BMI}$ in the extreme $\left(\mathrm{BMI} \geq 40 \mathrm{~kg} / \mathrm{m}^{2}\right) v$. super$\left(\mathrm{BMI} \geq 50 \mathrm{~kg} / \mathrm{m}^{2}\right.$ ) obese range. In women seeking bariatric surgery, food insecurity is associated with more severe obesity which can complicate bariatric procedures and increase the risk of peri- and postoperative morbidity and mortality ${ }^{(44,45)}$.

Participants responded to questions assessing the frequency of potentially surgery-interfering behaviours previously linked to food insecurity. Food-insecure participants were more likely to report eating fast food when their money ran out, lacking time and transportation to buy groceries, buying large amounts of food at the beginning of the month and running out, and the perception that buying bariatric vitamins and supplements would pose a financial hardship. All of these behaviours were endorsed by $40-50 \%$ of food-insecure participants and by very few food-secure participants (e.g. fewer than $8 \%$ ). Among participants with marginal food security, shopping at fast-food restaurants when money ran out and concerns about being able to afford vitamins, supplements and food after surgery were endorsed by approximately a third. Running out of food at the end of the month was less common among marginally food-secure participants, which is consistent with the definition of marginal food security as being characterized by worry about access to food, but not necessarily by scarcity.

Both food-insecure and marginally food-secure patients were more likely to report purchasing 'unhealthy' foods; however, this was less specific to food-insecure participants than the other four items related to shopping habits/perceptions, as it was endorsed by $60 \%$ of foodsecure participants. This may be due to the ambiguous wording of the item, which refers to buying unhealthy foods that are cheaper' rather than 'buying unhealthy foods because they are cheaper'. Despite this, food-secure participants still reported 'healthier' food shopping habits than participants with either marginal food insecurity or food insecurity, while a majority of all participants acknowledged that they often purchased 'unhealthy' foods.

Adherence to the postsurgical diet involves several behaviours that, based on the current results, could be influenced by food insecurity in this population. Behaviours such as eliminating most fried and processed foods, using protein supplements and multivitamins to compensate for reduced intake and (in some cases) malabsorption, and adhering to a regular schedule of eating and drinking with no skipped meals may be more challenging for those with food insecurity ${ }^{(46)}$. Food-insecure patients may be at increased risk for complications and poor weight-loss outcomes, including dehydration and weight loss plateauing from skipping meals during periods of 
scarcity, weight gain or dumping symptoms due to overconsumption early in the month or to reliance on cheap high-fat or high-sugar processed foods, and muscle loss or malnutrition from failing to use vitamins, fortified foods and protein supplements as recommended.

These results, while preliminary, based on a relatively small sample and limited to a single medical centre, suggest that food insecurity and marginal food security are more common among bariatric patients than the general population. Bariatric surgery is a cost-effective ${ }^{(47,48)}$, life-extending procedure with well-established health benefits including reversal of type 2 diabetes, improvements in hypertension and sleep apnoea, and greater mobility and overall quality of life ${ }^{(25,49-51)}$. Surveys of prospective bariatric patients suggest that for the majority, the primary motivation to have surgery is not to lose weight, but to resolve obesity-related co-morbidities and improve overall quality of life ${ }^{(52)}$. Although this was not measured in our study, a common patient-reported motivation for surgery is to produce weight loss that is required to qualify for another qualityof-life improving surgery such as joint replacement or hernia repair ${ }^{(52)}$. While our results highlight possible behavioural risks for food-insecure people undergoing bariatric surgery, surgical weight loss might also help patients with food insecurity, for example by giving them a greater chance of recovery from type 2 diabetes, which people with food insecurity struggle to manage through diet and lifestyle changes ${ }^{(11-13)}$. Improvement in mobility and obesity-related co-morbidities might help to alleviate food insecurity after surgery by reducing health-care costs and improving patients' workforce participation.

\section{Limitations}

Despite several strengths, including a large, wellcharacterized bariatric sample that was fully representative of our clinic population, the present study was limited by lack of information regarding household income and monetary value of nutrition assistance benefits. Additionally, we did not assess specific dietary choices, instead focusing on overall shopping and eating patterns. Although our sample was broadly similar to a nationally representative bariatric sample, findings should be generalized beyond our Central Pennsylvania population with caution. More research on the prevalence and correlates of food insecurity in a range of bariatric samples is needed. Because of the relatively low sample size and exploratory nature of our hypotheses, we did not conduct multivariate analyses predicting food insecurity status. Future research should address whether there are differential demographic correlates of marginal food security $v$. food insecurity, and whether some demographic correlates are more strongly associated with food security status than others. In addition, because there were few single parents and relatively few men in our sample, analyses concerning gender and household composition as predictors of food insecurity should be interpreted with particular caution.

\section{Conclusions}

Despite the relatively high prevalence of obesity and cardiometabolic illness among adults with food insecurity, the present study is the first exploration of the prevalence of food insecurity in a bariatric sample. Our results suggest that this issue affects a high percentage of our bariatric patients. Future research should address the associations of bariatric food insecurity with presurgical weight and health status, as well as psychosocial factors including mood, anxiety and disordered eating patterns. In addition, the association of presurgical food insecurity with postsurgical weight loss, complications and adjustment should be studied to better understand the impact of surgery for this group of patients. The lack of information on food insecurity and postoperative outcomes is troubling, given the high prevalence in our sample, and more research is needed to understand potential postsurgical risks associated with food insecurity. This research should be focused on the behavioural mechanisms through which food insecurity might lead to postsurgical risks. This will help providers to tailor interventions to the needs of patients with food insecurity, potentially making surgery safer and more effective for this population. One such behavioural mechanism might be disordered eating; in general population studies, food insecurity has been shown to be a risk factor for disordered eating behaviour ${ }^{(19)}$.

Given the likelihood that food insecurity could interfere with bariatric-specific health maintenance behaviours, we recommend universal screening for food insecurity in bariatric populations using the USDA screening items, which had a $7 \%$ false negative rate for marginal food security but did not fail to identify any low or very low food security patients. We also recommend more research aimed at: (i) the development of pre- and postsurgical programmes to support this vulnerable patient population in making the diet and lifestyle changes necessary to succeed after surgery and minimize the risk of complications; and (ii) evaluating barriers to the use of existing nutrition assistance programmes. We found that most patients who received nutrition assistance benefits were still food insecure or marginally food secure. Public health research should continue to address the gaps in nutrition assistance coverage, and specifically how food-insecure bariatric patients experience and use their nutrition assistance benefits to meet their specific postoperative nutritional needs.

In the absence of clear evidence that bariatric surgery poses specific risks to food-insecure patients, the present study does not provide enough evidence to inform decision making around whether any patient should or should not be approved for bariatric surgery. Rather, it highlights the need for both clinicians and researchers to be sensitive 
to patients' food security status. Such sensitivity might result in some changes to preoperative programming; for instance, a longer preoperative period, during which interventions aimed at both improving food security and reducing disordered eating behaviour might be indicated in some patients without obesity-related co-morbidities. However, our hope is that the current research highlights the issue of food insecurity in this vulnerable population, spurring more research into interventions aimed both at alleviating food insecurity in pre- and postoperative bariatric populations and at improving pre-bariatric education to help food-insecure people make health behaviour changes in spite of their financial burdens.

\section{Acknowledgements}

Acknowledgements: The authors would like to express their gratitude to the Penn State Surgical Weight Loss Clinic staff for assisting with the data collection for this study. They would also like to thank the study participants who contributed their time for this project. Financial support: This work was supported by the Brad Hollinger Eating Disorder Research Endowment (grant number 900-12HY1940). The research endowment had no role in the design, analysis or writing of this article. Conflict of interest: The authors declare that there are no conflicts of interest. Authorship: J.A.P. and A.R. managed study recruitment, data collection and data entry. J.A.P. wrote the first draft with contributions from H.F.Z. and A.R. H.F.Z. analysed the data and wrote the Methods/Results sections. All authors reviewed and commented on subsequent drafts of the manuscript. Ethics of human subject participation: This study was conducted according to the guidelines laid down in the Declaration of Helsinki and the Institutional Review Board at Penn State College of Medicine approved all procedures involving human patients. Patients were given a Summary Explanation of Research and indicated their consent by completion of the research study questionnaires.

Author ORCID. (D) Julia A Price, 0000-0003-3783-6146.

\section{References}

1. Coleman-Jensen A, Gregory CA, Rabbitt MP et al. (2018) Household Food Security in the United States in 2017. Economic Research Report no. ERR-256. https://www.ers. usda.gov/webdocs/publications/90023/err-256.pdf?v=0 (accessed June 2019).

2. Laraia BA (2013) Food insecurity and chronic disease. Adv Nutr 4, 203-212.

3. Berkowitz SA, Berkowitz TSZ, Meigs JB et al. (2017) Trends in food insecurity for adults with cardiometabolic disease in the United States: 2005-2012. PLoS One 12, e0179172.
4. Gundersen C \& Ziliak JP (2015) Food insecurity and health outcomes. Health Aff (Millwood) 34, 1830-1839.

5. Coleman-Jensen A, Rabbitt MP, Gregory CA et al. (2018) Statistical Supplement to Household Food Security in the United States in 2017. Administrative Publication no. AP-079, p. 11. https://www.ers.usda.gov/webdocs/ publications/90029/ap-079.pdf? $v=0$ (accessed June 2019).

6. Ashby S, Kleve S, McKechnie R et al. (2016) Measurement of the dimensions of food insecurity in developed countries: a systematic literature review. Public Health Nutr 19, 28872896.

7. Nettle D, Andrews C \& Bateson M (2017) Food insecurity as a driver of obesity in humans: the insurance hypothesis. Behav Brain Sci 40, e105.

8. Epstein LH, Jankowiak N, Lin H et al. (2014) No food for thought: moderating effects of delay discounting and future time perspective on the relation between income and food insecurity. Am J Clin Nutr 100, 884-890.

9. Pan L, Sherry B, Njai R et al. (2012) Food insecurity is associated with obesity among US adults in 12 states. J Acad Nutr Diet 112, 1403-1409.

10. Seligman HK, Bindman AB, Vittinghoff E et al. (2007) Food insecurity is associated with diabetes mellitus: results from the National Health Examination and Nutrition Examination Survey (NHANES) 1999-2002. J Gen Intern Med 22, 1018-1023.

11. Shalowitz MU, Eng JS, McKinney CO et al. (2017) Food security is related to adult type 2 diabetes control over time in a United States safety net primary care clinic population. Nutr Diabetes 7, e277.

12. Lyles CR, Wolf MS, Schillinger D et al. (2013) Food insecurity in relation to changes in hemoglobin A1c, self-efficacy, and fruit/vegetable intake during a diabetes educational intervention. Diabetes Care 36, 1448-1453.

13. Berkowitz SA, Gao X \& Tucker KL (2014) Food-insecure dietary patterns are associated with poor longitudinal glycemic control in diabetes: results from the Boston Puerto Rican Health Study. Diabetes Care 37, 2587-2592.

14. Franklin B, Jones A, Love D et al. (2012) Exploring mediators of food insecurity and obesity: a review of recent literature. J Community Health 37, 253-264.

15. Drewnowski A \& Specter SE (2004) Poverty and obesity: the role of energy density and energy costs. Am J Clin Nutr 79, 6-16.

16. Bhattacharya J, Currie J \& Haider S (2004) Poverty, food insecurity, and nutritional outcomes in children and adults. J Health Econ 23, 839-862.

17. Hanson KL \& Connor LM (2014) Food insecurity and dietary quality in US adults and children: a systematic review. $A m J$ Clin Nutr 100, 684-692.

18. Mello JA, Gans KM, Risica PM et al. (2010) How is food insecurity associated with dietary behaviors? An analysis with low-income, ethnically diverse participants in a nutrition intervention study. J Am Diet Assoc 110, 1906-1911.

19. Becker CB, Middlemass K, Taylor B et al. (2017) Food insecurity and eating disorder pathology. Int J Eat Disord 50, $1031-1040$.

20. Martin KS \& Ferris AM (2007) Food insecurity and gender are risk factors for obesity. J Nutr Educ Behav 39, 31-36.

21. Van Gaal LF \& Maggioni AP (2014) Overweight, obesity, and outcomes: fat mass and beyond. Lancet 383, 935-936.

22. Gloy VL, Briel M, Bhatt DL et al. (2013) Bariatric surgery versus non-surgical treatment for obesity: a systematic review and meta-analysis of randomised controlled trials. BMJ 347, f5934.

23. Sjöström L, Lindroos A-K, Peltonen M et al. (2004) Lifestyle, diabetes, and cardiovascular risk factors 10 years after bariatric surgery. N Engl J Med 351, 2683-2693. 
24. Sjöström L, Narbro K, Sjöström CD et al. (2007) Effects of bariatric surgery on mortality in Swedish obese subjects. NEnglJ Med 357, 741-752.

25. Sarkhosh K, Switzer NJ, El-Hadi M et al. (2013) The impact of bariatric surgery on obstructive sleep apnea: a systematic review. Obes Surg 23, 414-423.

26. Chang S-H, Stoll CRT, Song J et al. (2014) The effectiveness and risks of bariatric surgery: an updated systematic review and meta-analysis, 2003-2012. JAMA Surg 149, 275-287.

27. Aills L, Blankenship J, Buffington C et al. (2008) ASMBS allied health nutritional guidelines for the surgical weight loss patient. Surg Obes Relat Dis 4, 5 Suppl., S73-S108.

28. Heber D, Greenway FL, Kaplan LM et al. (2010) Endocrine and nutritional management of the post-bariatric surgery patient: an endocrine society clinical practice guideline. J Clin Endocrinol Metab 95, 4823-4843.

29. Ziegler O, Sirveaux MA, Brunaud L et al. (2009) Medical follow up after bariatric surgery: nutritional and drug issues. General recommendations for the prevention and treatment of nutritional deficiencies. Diabetes Metab 35, 544-557.

30. Parrott J, Frank L, Rabena R et al. (2017) American Society for Metabolic and Bariatric Surgery integrated health nutritional guidelines for the surgical weight loss patient 2016 update: micronutrients. Surg Obes Relat Dis 13, 727-741.

31. Tucker ON, Szomstein S \& Rosenthal RJ (2007) Nutritional consequences of weight-loss surgery. Med Clin North Am 91, 499-514.

32. Andreu A, Moizé V, Rodríguez L et al. (2010) Protein intake, body composition, and protein status following bariatric surgery. Obes Surg 20, 1509-1515.

33. Bickel G, Nord M, Price C et al. (2000) Guide to Measuring Household Food Security, Revised 2000. https://fns-prod. azureedge.net/sites/default/files/FSGuide.pdf (accessed September 2018).

34. Wadden TA \& Foster GD (2006) Weight and Lifestyle Inventory (WALI). Obesity (Silver Spring) 14, Suppl. 2, 99S-118S

35. US Census Bureau (2012) Qualifying Urban Areas for the 2010 Census. Fed Regist 77, issue 59, 18651-18669; available at https://www.federalregister.gov/documents/2012/03/27/ 2012-6903/qualifying-urban-areas-for-the-2010-census

36. US Census Bureau (2017) American FactFinder: Annual Estimates of the Resident Population: April 1, 2010 to July 1 , 2016: 2016 Population Estimates. https://factfinder.census. gov/faces/tableservices/jsf/pages/productview.xhtml?src= bkmk (accessed September 2018).

37. US Department of Agriculture, Economic Research Service (2017) Food Access Research Atlas: About the Atlas. https:// www.ers.usda.gov/data-products/food-access-research-atlas/ about-the-atlas/ (accessed September 2018).

38. Internal Revenue Service (2017) SOI Tax Stats - Individual Income Tax Statistics - ZIP Code Data (SOI): Individual Income Tax ZIP Code Data. https://www.irs.gov/statistics/ soi-tax-stats-individual-income-tax-statistics-zip-code-data-soi (accessed September 2018).

39. Liese AD, Ma X, Hutto B et al. (2017) Food shopping and acquisition behaviors in relation to BMI among residents of low-income communities in South Carolina. Int J Environ Res Public Health 14, 1075.

40. Champely S, Ekstrom C, Dalgaard P et al. (2018) Basic Functions for Power Analysis. https://cran.r-project.org/ web/packages/pwr/pwr.pdf (accessed September 2018).

41. Kizy S, Jahansouz C, Downey MC et al. (2017) National trends in bariatric surgery 2012-2015: demographics, procedure selection, readmissions, and cost. Obes Surg 27, 2933-2939.

42. Hernandez DC, Reesor L \& Murillo R (2017) Gender disparities in the food insecurity-overweight and food insecurityobesity paradox among low-income older adults. J Acad Nutr Diet 117, 1087-1096.

43. Townsend MS, Peerson J, Love B et al. (2001) Food insecurity is positively related to overweight in women. J Nutr 131, $1738-1745$.

44. DeMaria EJ, Portenier D \& Wolfe L (2007) Obesity surgery mortality risk score: proposal for a clinically useful score to predict mortality risk in patients undergoing gastric bypass. Surg Obes Relat Dis 3, 134-140.

45. Parikh MS, Shen R, Weiner M et al. (2005) Laparoscopic bariatric surgery in super-obese patients (BMI>50) is safe and effective: a review of 332 patients. Obes Surg 15, 858-863.

46. Sarwer DB, Wadden TA, Moore RH et al. (2008) Preoperative eating behavior, postoperative dietary adherence, and weight loss after gastric bypass surgery. Surg Obes Relat Dis 4, 640-646.

47. Christou NV, Sampalis JS, Liberman M et al. (2004) Surgery decreases long-term mortality, morbidity, and health care use in morbidly obese patients. Ann Surg 240, 416-423.

48. Picot J, Jones J, Colquitt JL et al. (2009) The clinical effectiveness and cost-effectiveness of bariatric (weight loss) surgery for obesity: a systematic review and economic evaluation. Health Technol Assess 13, issue 41, 1-190, 215-357, iii-iv.

49. Arterburn D, Bogart A, Coleman KJ et al. (2013) Comparative effectiveness of bariatric surgery vs. nonsurgical treatment of type 2 diabetes among severely obese adults. Obes Res Clin Pract 7, e258-e268.

50. Zhang Y, Wang J, Ju W et al. (2015) Laparoscopic sleeve gastrectomy versus laparoscopic Roux-en-Y gastric bypass for morbid obesity and related comorbidities: a meta-analysis of 21 studies. Obes Surg 25, 19-26.

51. Courcoulas AP, King WC, Belle SH et al. (2018) Seven-year weight trajectories and health outcomes in the Longitudinal Assessment of Bariatric Surgery (LABS) study. JAMA Surg 153, 427-434.

52. Munoz DJ, Lal M, Chen EY et al. (2007) Why patients seek bariatric surgery: a qualitative and quantitative analysis of patient motivation. Obes Surg 17, 1487-1491. 